\title{
Late complications caused by the neglected biliary stent
}

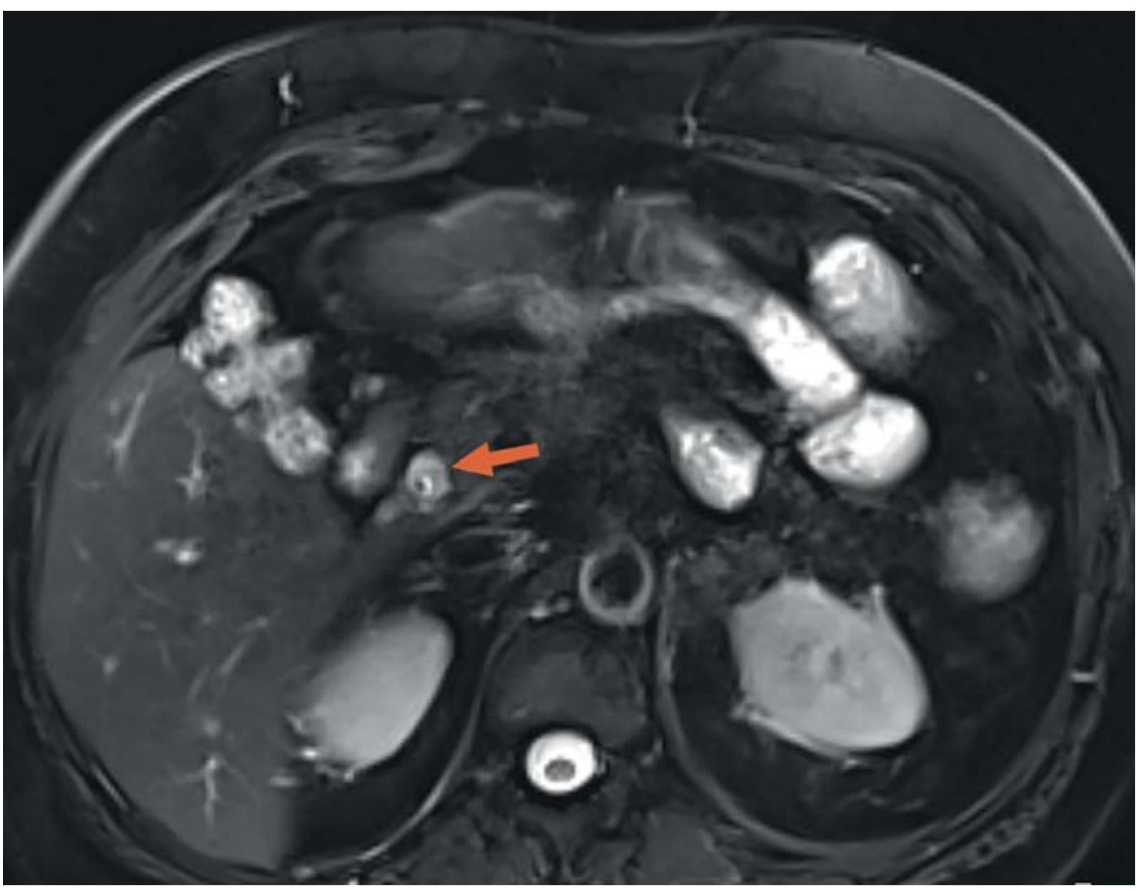

- Fig. 1 Magnetic resonance cholangiopancreatography revealed a dilated common bile duct with multiple stones and a neglected biliary stent (arrow).

A 50-year-old woman was admitted with fever, jaundice, and abdominal pain. She was diagnosed with acute cholangitis secondary to a neglected biliary stent. Previous history included placement of a double-pigtail stent 6 years earlier for choledocholithiasis, to be followed by an elective cholecystectomy. However, she had not attended the follow-up appointment for biliary stent removal. Upon admission, a magnetic resonance cholangiopancreatography was done ( $\triangleright$ Fig. 1). During endoscopic retrograde cholangiopancreatography, the proximal end of the biliary stent was seen in the lumen of the duodenal bulb ( $\mathbf{F i g . 2}$ ), and the distal end was seen at the papilla. The cholangiogram showed that the common bile duct was dilated with multiple filling defects, and the proximal end of the biliary stent was out of the biliary system ( $\mathbf{F i g . 3}$ ). The stent had caused the formation of a fistula between the common hepatic duct and the duodenal bulb. This was further supported by the ease of passing the guidewire through the fistula after removal of the stent ( $\triangleright$ Fig.4). A narrowing of the confluence of the hepatic ducts was also demonstrated (> Fig. 5).

Subsequently, all calculi were removed and a 5-Fr nasobiliary tube was placed in the left hepatic duct. The patient recovered uneventfully, and the tube was removed 2 days later ( $\triangleright$ Video 1 ).

Late complications of biliary stent placement are stent dysfunction, stent migration, biliary cast formation, and less frequently, duodenal perforation and bleeding $[1,2]$. Choledochoduodenal fistula occurring between the common hepatic duct and duodenal bulb due to neglected stent is rare. In this case, chronic irritation by the stent had induced inflammation and led to narrowing of the confluence of the hepatic ducts. Although the fistula

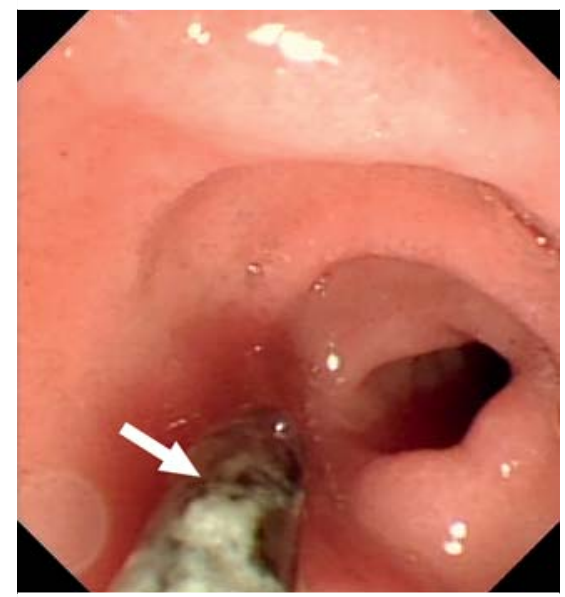

Fig. 2 The proximal end of the biliary stent (arrow) was seen at the duodenal bulb during endoscopy.

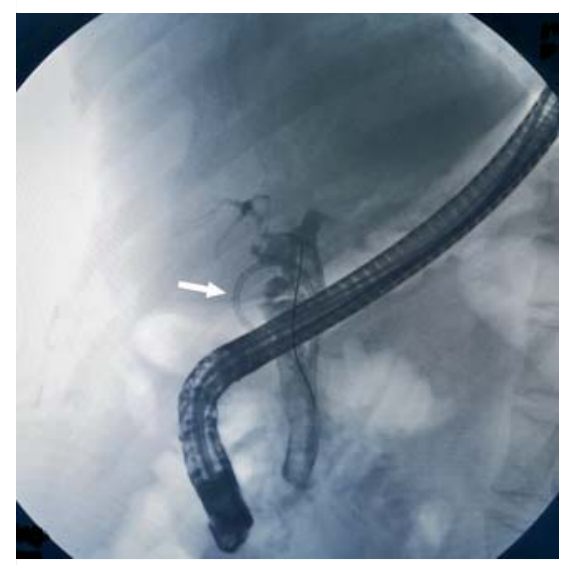

Fig. 3 The fluoroscopy image showed that the common bile duct was dilated with multiple filling defects (arrow). The proximal end of the pigtail biliary stent was located outside the contrast-filled biliary system.

is expected to heal uneventfully after stent removal, the stricture may worsen over time and cause recurrent cholangitis. A watchful waiting strategy was planned for this patient.

Endoscopy_UCTN_Code_CPL_1AK_2AD 


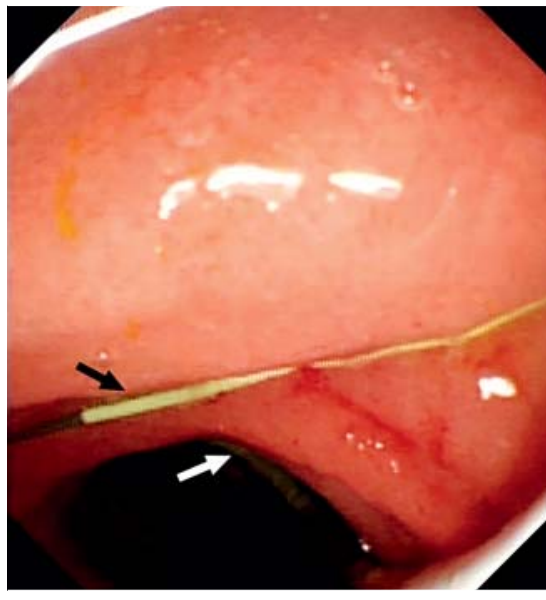

Fig. 4 The guidewire (black arrow) passed through the fistula (white arrow) into the duodenum.

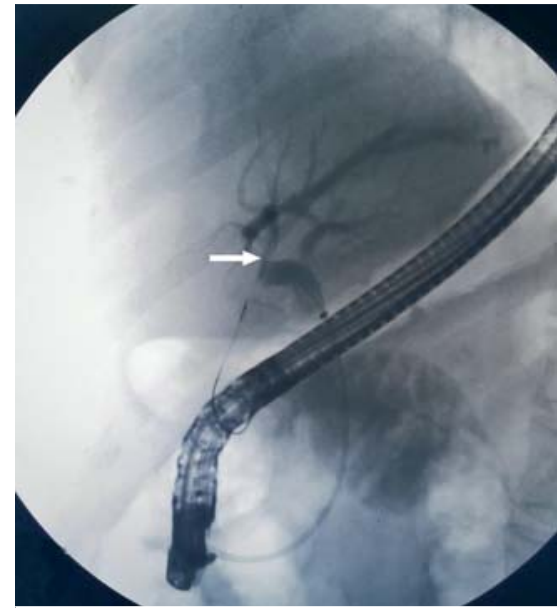

Fig. 5 The hepatic duct was deformed into a right angle (arrow), and the confluence of left and right hepatic ducts was narrowed.

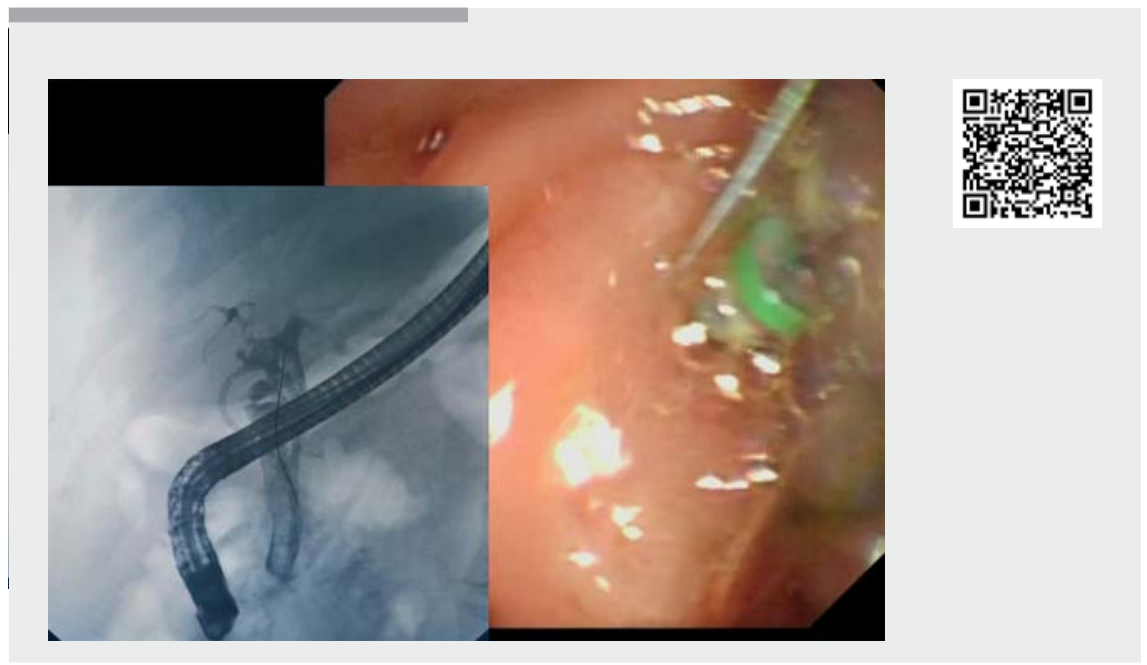

$\checkmark$ Video 1 The biliary duct, which had been neglected for 6 years, and common bile duct stones were cleared during endoscopic retrograde cholangiopancreatography. A fistula between the common hepatic duct and duodenal bulb was demonstrated.

\section{Acknowledgment}

This work was financially supported by the Bethune Charitable Foundation (NO.HZB20181119-34)

\section{Competing interests}

The authors declare that they have no conflict of interest.

\section{The authors}

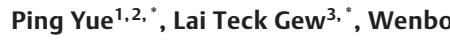
Meng ${ }^{1,2}$, Xun Li ${ }^{2,4}$

1 Department of Special Minimally Invasive Surgery, The First Hospital of Lanzhou University, Lanzhou, Gansu, China

2 The First Clinical Medical School of Lanzhou University, Lanzhou, Gansu, China

3 Gastroenterology Unit, Department of Medicine, Hospital Kuala Lumpur, Kuala Lumpur, Malaysia

4 The Fifth Department of General Surgery, The First Hospital of Lanzhou University, Lanzhou, Gansu, China

* These authors contributed equally to this work.
Corresponding author

\section{Wenbo Meng, MD, PhD}

Department of Special Minimally Invasive Surgery, The First Hospital of Lanzhou University, No.1 DongGang West Road, LanZhou, Gansu 730030, China

Fax: +86-931-8356032

mengwb@lzu.edu.cn

\section{References}

[1] Sohn SH, Park JH, Kim KH et al. Complications and management of forgotten longterm biliary stents. World J Gastroenterol 2017; 23: 622-628

[2] Kumar S, Chandra A, Kulkarni R et al. Forgotten biliary stents: ignorance is not bliss. Surg Endosc 2018; 32: 191-195

\section{Bibliography}

Endoscopy 2020; 52: E406-E407

DOI 10.1055/a-1138-0188

ISSN 0013-726X

published online 17.4.2020

(C) 2020. Thieme. All rights reserved.

Georg Thieme Verlag KG, Rüdigerstraße 14, 70469 Stuttgart, Germany

\section{ENDOSCOPY E-VIDEOS}

https://eref.thieme.de/e-videos

口回 Endoscopy E-Videos is a free access online section, reporting 向社 on interesting cases and new

techniques in gastroenterological endoscopy. All papers include a high quality video and all contributions are freely accessible online.

This section has its own submission website at https://mc.manuscriptcentral.com/e-videos 